\title{
Mortality in relation to cigarette and pipe smoking: 16 years' observation of 25000 Swedish men*
}

\author{
JOHN M CARSTENSEN, GÖRAN PERSHAGEN, AND GUNNAR EKLUND
}

From the Department of Cancer Epidemiology, Radiumhemmet, Karolinska University Hospital, Box 60500, S-104 01 Stockholm, Sweden and the Department of Epidemiology, National Institute of Environmental Medicine, Box 60208, S-104 01 Stockholm, Sweden

SUMMARY In a random sample of 25129 Swedish men who responded to a questionnaire on smoking habits in 1963 the cause specific mortality was followed through 1979 . In the cohort, $32 \%$ smoked cigarettes, $27 \%$ a pipe, and $5 \%$ cigars. There were clear covariations $(p<0.001)$ between the amount of tobacco smoked and the risk of death due to cancer of the oral cavity and larynx, oesophagus, liver, pancreas, lung, and bladder as well as due to bronchitis and emphysema, ischaemic heart disease, aortic aneurysm, and peptic ulcer. Pipe smokers showed similar risk levels to cigarette smokers. There was a close to linear increase in lung cancer risk in relation to the amount of tobacco smoked for cigarette, pipe, and cigar smokers, respectively. An increasing risk of ischaemic heart disease with amount smoked was seen among both cigarette and pipe smokers. A similar fraction of inhalers in Swedish cigarette and pipe smokers may explain the similarity in risks.

Tobacco smoking is an important cause of morbidity and mortality in many countries. This knowledge has evolved from numerous epidemiological investigations, which in general show great consistency in results. ${ }^{1}$ There are, however, some discrepant findings in relation to the risks associated with various forms of tobacco use. Thus, the large cohort studies from Canada, ${ }^{2}$ the United Kingdom, ${ }^{3}$ and the United States ${ }^{4-6}$ show a considerably lower risk of lung cancer for pipe and cigar smokers than for cigarette smokers, whereas data from Germany, ${ }^{7}$ Switzerland, ${ }^{8}$ and Sweden ${ }^{9}{ }^{10}$ indicate similar risks for different types of smoking.

To investigate the health risks associated with different types of smoking a cohort study was initiated in a random sample of about 55000 Swedish men and women. ${ }^{11}$ A special feature of the cohort is that among men pipe smoking was nearly as common as cigarette smoking, $27 \%$ versus $32 \%$. Five per cent of the men were cigar smokers. There are two earlier reports regarding mortality rates in the cohort, covering deaths through 1968 and 1972, respectively. ${ }^{9}{ }^{12}$ In the present report of the mortality experience in males through December 1979, including more than twice as many deaths as in the earlier reports, emphasis is

* Supported by grants from the Swedish Medical Research Council and from the King Gustaf V Jubilee Fund. placed on a comparison between cigarette and pipe smoking.

\section{Material and methods}

In 1963, 55879 persons born between 1894 and 1945 were selected as an age-stratified random sample from the computer-based register comprising the 1960 Swedish population census. The sampling fraction was $0.7 \%$ among those born after 1913 and $1.8 \%$ in the older groups. Questionnaires on smoking habits, occupation, occupation of husband/wife, family income, and marital status were mailed in March 1963 to those in the sample not reported as dead. After three mailed reminders and supplementary telephone and home interviews a response rate of $94 \%$ was obtained. An extensive account of the results from the 1963 survey and details on the methods of data collection are given elsewhere. ${ }^{11}$

Questions were included regarding the quantity of tobacco smoked, with five to seven fixed response alternatives, divided by present and former habits in each of three periods from 1954 and by type of tobacco. There were also questions about the most usual brand smoked (by type of tobacco), age when started smoking regularly ("daily or almost daily"), years smoked regularly (with seven fixed response 
alternatives), and, if cigarette smoker, whether he/she inhaled deeply, lightly, or did not inhale at all. A translation of the questionnaire is given by Cederlöf $e t$ al. ${ }^{9}$

Mainly for the purpose of validating the answers concerning former smoking habits, current and former smokers aged 40-59 in the 1963 survey were selected for another mail survey in 1969. The questions in the 1969 survey were essentially the same as in 1963 except that smoking habits were investigated for the years 1963 and 1969 only. The response rate was $95 \%$. Cederlöf $e t a l^{9}$ give a summary of the results of the 1969 survey.

The 1963 cohort has been successively updated with information regarding deaths from the national Cause of Death Register of the Central Bureau of Statistics, which collects and codes all death certificates in Sweden. This has been done by means of computerised record linkages using the ten-digit civic registration number, which is unique for every person living in Sweden. Underlying and contributing causes of deaths were classified according to the 7 th revision of the International Classification of Diseases (ICD) ${ }^{13}$ until 1968, and from 1969 according to the 8th revision. ${ }^{14}$ Our analysis of cause-specific mortality in males is restricted to the underlying cause of death. We have translated all causes or groups of causes coded according to the 7th revision to the 8th with the use of a translation list produced by the Central Bureau of Statistics. ${ }^{15}$

In the analysis we have excluded all men who died during 1963, thus obtaining a "latency" period of at least half a year. Three percent of the males alive on 1 January 1964 were excluded because of missing or inconsistent answers on questions regarding form of tobacco use in 1963, quantity smoked in 1963, and age when started smoking, leaving 25129 men in the analysis.

The answers regarding quantities smoked (number of cigarettes, etc) were given in the form of ranges. To obtain a single grams-of-tobacco-smoked-per-day variable we assigned a gram-per-day value to each category, considering one cigarette as equivalent to $1 \mathrm{~g}$ tobacco, and cigars as $\mathbf{3} \mathrm{g}$ if small or $5 \mathrm{~g}$ if large. The quantities of the different types of tobacco were then added together. For example, concerning the smoking habits in 1963 the following quantifications were made: $1-3,4-7,8-15,16-25$, and more than 25 cigarettes per day equals $2,5,12,20$, and $33 \mathrm{~g}$ tobacco, respectively; $1,2-4$, and more than 4 large cigars per day equals 5,15 and $30 \mathrm{~g}$, respectively; a package of pipe tobacco $(50 \mathrm{~g})$ lasting $10-20,5-9$, and $1-4$ days equals 4,8 and $16 \mathrm{~g}$ a day, respectively. Subjects who had smoked regularly during any period before 1963 but not in 1963 were classified as ex-smokers.
A comparison of inhalation in cigarette and pipe smokers was made using data in the Swedish twin register. This register contains about 11000 same sexed twin pairs born between 1886 and $1925 .{ }^{16}$ The twins were identified from birth certificates and a questionnaire mailed in 1961, primarily to determine zygosity and smoking habits. Detailed information on smoking habits, including data on inhalation, was obtained through a second questionnaire mailed in 1967 or $1970 .{ }^{17}$ This has been used in the present analysis.

Indirectly standardised cause-specific mortality rates were calculated for the different groups defined by smoking habits. The rates were standardised for both age-at-risk, using five-year age groups, and residence, using three categories: major towns (Stockholm, Gothenburg, and Malmö), other towns, and rural districts. In most cases we have chosen to present the results in the form of relative rates calculated by dividing the standardised rates of the different smoking habits categories by those of the reference group, ie, never smokers. Mantel-Haenszel tests (with correction for continuity) for differences between two standardised rates ${ }^{18}$ and for trends in the rates ${ }^{19}$ have been calculated. A chi-square value above $3.84(p<0.05)$ was considered statistically significant. For some of the smoking habit categories we calculated the mean grams of tobacco smoked per day in 1963 standardised for age and residence, using weights proportional to the total number of deaths (irrespective of cause) in each group defined by age and residence.

\section{Results}

In table 1 cause-specific standardised relative death rates for the period 1964-79 are displayed for different smoking habit categories defined by amount of tobacco smoked in 1963. For never-smokers, who constitute the reference group, standardised annual rates per 100000 men are given. In 13 out of the 27 causes listed in table 1 statistically significant increasing trends in mortality with tobacco consumption were found. High risk gradients were seen for several cancer sites. Cancer of the oral cavity/larynx, lung, oesophagus, liver, pancreas, and bladder each showed a highly significant trend $(p<0.001)$ in the rates. Among the other diseases studied, bronchitis and emphysema, ischaemic heart disease, non-syphilitic aortic aneurysm, and peptic ulcer displayed a death rate that was strongly correlated $(p<0.001)$ with the amount smoked.

In table 1 the standardised relative death rates of ex-smokers are also shown. The point estimates of the relative death rates exceed 1 for all the causes of death 
Table 1 Death rate in a cohort of 25129 Swedish men, 1964-79, by cause of death and smoking habits*

\begin{tabular}{|c|c|c|c|c|c|c|}
\hline \multirow{3}{*}{$\begin{array}{l}\text { Cause of death } \\
\text { (8th revision ICD numbers) }\end{array}$} & \multirow{3}{*}{$\begin{array}{l}\text { Death rate } \\
\text { per } 100000 \\
\text { person years } \\
\text { Never-smokers }\end{array}$} & \multicolumn{4}{|c|}{ Relative death ratet } & \multirow{3}{*}{$\begin{array}{l}\text { Chi-square } \\
\text { value } \$\end{array}$} \\
\hline & & \multirow[t]{2}{*}{ Ex-smokers } & \multicolumn{3}{|c|}{ Current smokers, any tobacco (g/day) } & \\
\hline & & & $1-7$ & $8-15$ & $>15$ & \\
\hline Cancer of oral cavity and larynx $(140-146,148,161)$ & $3.6(4)$ & $2 \cdot 3(6)$ & $1.4(2)$ & $2.5 \quad(7)$ & $6.3(10)$ & $12 \cdot 7$ \\
\hline Cancer of oesophagus (150) & $4 \cdot 3(5)$ & $1 \cdot 3$ (4) & $1 \cdot 1$ (2) & $4 \cdot 5$ (15) & 5.4 (11) & $16 \cdot 2$ \\
\hline Cancer of stomach (151) & $59.9(78)$ & 0.8 (33) & $1 \cdot 1 \quad(28)$ & $0.9(39)$ & $1.5(32)$ & 1.4 \\
\hline Cancer of colon (153) & $27 \cdot 2(35)$ & $1 \cdot 1 \quad(22)$ & $1.4(16)$ & $1.5(29)$ & $1.5(15)$ & $3 \cdot 3$ \\
\hline Cancer of liver and biliary passages (155-156) & $7 \cdot 5(9)$ & $1.7(9)$ & $1.6(5)$ & $3 \cdot 3(18)$ & $4 \cdot 1$ (13) & 13.8 \\
\hline Cancer of pancreas (157) & $16.5(20)$ & $1.8 \quad(21)$ & $2 \cdot 2$ (15) & $2 \cdot 1 \quad(26)$ & $2.6(19)$ & $12 \cdot 0$ \\
\hline Cancer of trachea, bronchus and lung (162) & $19 \cdot 6(23)$ & $1 \cdot 1$ (15) & 3.4 (28) & 7.5 (113) & $11.9(97)$ & 191.0 \\
\hline Cancer of prostate (185) & $57 \cdot 1(77)$ & 1.0 & $1 \cdot 1 \quad(26)$ & 0.8 (31) & 0.9 (15) & 0.7 \\
\hline Cancer of bladder (188) & $8.8(11)$ & $1.8 \quad(11)$ & 3.0 (11) & $3 \cdot 3 \quad(22)$ & $3 \cdot 2(10)$ & $11 \cdot 8$ \\
\hline $\begin{array}{l}\text { Cancer of kidney and other urinary organs (189) } \\
\text { Neoplasms of lymphatic and }\end{array}$ & $16 \cdot 7(21)$ & $1.3 \quad(15)$ & 1.9 (13) & $1 \cdot 1 \quad(14)$ & $1.2(8)$ & $0 \cdot 2$ \\
\hline haematopoetic tissue $(200-209)$ & $46 \cdot 2(59)$ & $0.8 \quad(24)$ & $0.4(8)$ & $0.9(30)$ & $1.0 \quad(18)$ & 0.0 \\
\hline Other and unspecified cancers & $44 \cdot 8(55)$ & 1.0 & $0.7(12)$ & 0.8 (27) & $1.6(31)$ & $1 \cdot 7$ \\
\hline Cerebrovascular disease $(430-438)$ & $159.0(210)$ & $1 \cdot 1 \quad(124)$ & $0.9(58)$ & $0.9(98)$ & $1 \cdot 1 \quad(59)$ & 0.0 \\
\hline Aortic aneurysm (non-syphilitic) (441) & $11 \cdot 6(15)$ & $1.4(12)$ & 1.7 (8) & $2 \cdot 7$ (22) & 3.0 (11) & $12 \cdot 6$ \\
\hline Other diseases of circulatory system & $98 \cdot 1(125)$ & $1 \cdot 1 \quad(75)$ & 0.9 (37) & $1 \cdot 1 \quad(75)$ & $1 \cdot 3$ (49) & $2 \cdot 2$ \\
\hline Pneumonia (480-486) & $32 \cdot 7(44)$ & $0.6(15)$ & $1 \cdot 3(18)$ & $1.0 \quad(24)$ & $1.7 \quad(17)$ & 1.4 \\
\hline Bronchitis and emphysema $(490-492)$ & $10 \cdot 4(13)$ & 1.8 (14) & $1.9(8)$ & $2.9(22)$ & $5 \cdot 3(20)$ & $25 \cdot 3$ \\
\hline Asthma (493) & $11.4(15)$ & 0.8 (6) & $1 \cdot 3(6)$ & $1.0(8)$ & $0.5(2)$ & 0.5 \\
\hline Other respiratory diseases & $7.6(10)$ & $1.6(9)$ & 0.9 (3) & 2.4 (13) & $2.9 \quad(7)$ & $6 \cdot 6$ \\
\hline Peptic ulcer (531-534) & $10 \cdot 5(13)$ & $1 \cdot 2(9)$ & $1.6(7)$ & 2.4 (19) & $3.7 \quad(15)$ & $13 \cdot 3$ \\
\hline Cirrhosis of liver (571) & $17 \cdot 2(18)$ & 1.6 (18) & 0.8 (5) & $1.0 \quad(14)$ & $2 \cdot 3 \quad(24)$ & 6.4 \\
\hline Other digestive diseases & $25 \cdot 7(33)$ & 0.9 (17) & $1.4(15)$ & $1.0(19)$ & $1.4(13)$ & 0.6 \\
\hline Diseases of urinary system (580-599) & $23 \cdot 5(32)$ & $1.4(25)$ & $1.5 \quad(15)$ & $0.7(11)$ & $0.9(6)$ & 0.5 \\
\hline Other diseases & $99 \cdot 6(125)$ & $1 \cdot 1 \quad(73)$ & 0.7 (27) & $1.0(75)$ & $1 \cdot 1 \quad(42)$ & $0 \cdot 0$ \\
\hline Suicide, accidents and violence (E800-E999) & $96 \cdot 8(120)$ & $0.8 \quad(47)$ & $1.4(55)$ & $1.4(102)$ & $1 \cdot 5 \quad(71)$ & $7 \cdot 3$ \\
\hline All causes & $1518.0(1936)$ & $1.08(1170)$ & $1 \cdot 21(758)$ & $1 \cdot 35(1494)$ & $1 \cdot 70(955)$ & $199 \cdot 4$ \\
\hline
\end{tabular}

* Death rates standardised for age and residence. Numbers of deaths are given in parentheses.

+ Never-smokers constitute the reference group.

$\ddagger$ Test for trend. Ex-smokers are excluded and the remaining groups are coded 1, 2, 3, and 4, respectively.

reported above as strongly correlated with tobacco consumption. For ischaemic heart disease and all deaths (irrespective of cause) there is a significantly higher $(p<0.05)$ death rate in ex-smokers than in never-smokers.

For ischaemic heart disease we also studied the relation between smoking and death rate at different ages. The relative rate of smokers (with never-smokers as reference group) showed a clear dependence on age at risk. Thus, for ages under 45 the relative death rate due to ischaemic heart disease was estimated at 5.98 (95\% confidence interval: 1.43-53.3) compared to $1.09(0.91-1.31)$ for smokers of 75 years or older.

In tables 2 and 3 only 12 out of the 27 causes of death listed in table 1 are retained. These 12 causes include the ten causes which gave highly significant results $(p<0.001)$ in the trend tests of table 1 as well as cirrhosis of the liver and suicide, accidents, and violence. In table 2 the relative death rates by type of tobacco used are presented for each of the 12 causes. About $10 \%$ of the cigarette, pipe or cigar only smokers in 1963 had changed their smoking habits since 1954 and were thus excluded in the analysis. Smokers who had changed their form of tobacco use according to the 1969 questionnaire contributed with person-time only until 31 December 1969 . For most causes the rates are similar for the different types of smoking. There is, however, a lower risk of death from suicide, accidents, and violence for pipe smokers than for cigarette smokers $(p<0.05)$. A similar tendency can also be seen for cirrhosis of the liver.

The standardised relative lung cancer death rate by amount smoked and by type of tobacco used in 1963 is shown in figure 1 . There is a striking similarity in the lung cancer death rates given quantity smoked between the different types of tobacco use. The rates show a close to linear increase in relation to the amount of tobacco smoked, without any sign of a threshold in the low consumption categories. The corresponding rates for ischaemic heart disease have been plotted in figure 2 . The death rate of ischaemic heart disease increases with amount of tobacco smoked among both pure cigarette users and pure pipe users, but for the pure cigar smokers there is no clear trend. 


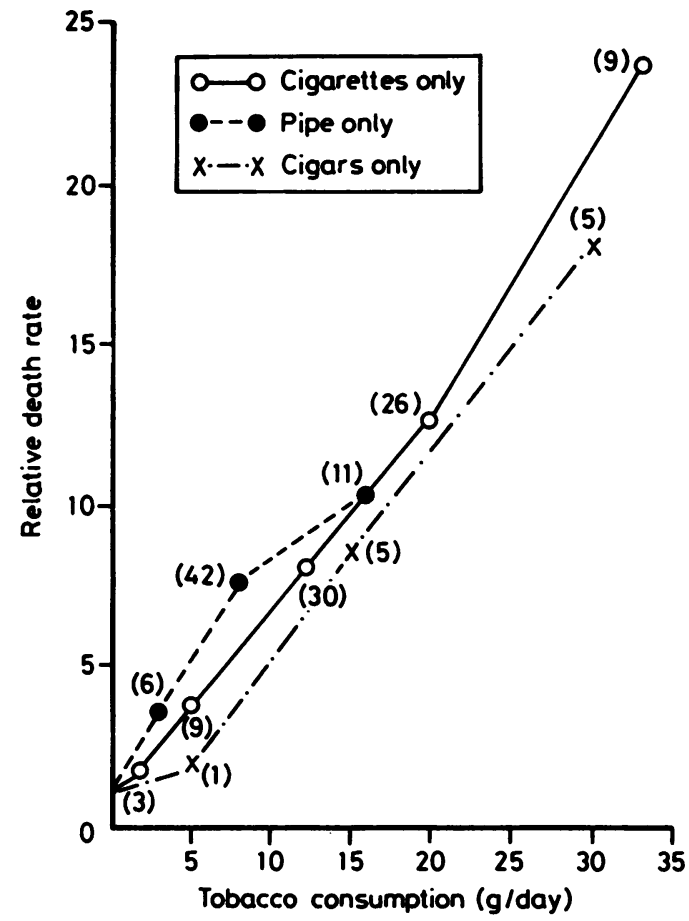

Fig 1 Relative death rate for cancer of the trachea, bronchus, and lung in Swedish men in relation to amount and type of smoking. (Death rates are standardised for age and residence with never-smokers as reference. Number of deaths are given in parentheses).

In table 3 the effects of age when started smoking on the death rates are shown. The rates are standardised for age, residence, and amount smoked in 1963 . There are significantly increasing trends in the relative rates with lower starting age for cancer of the lung $(p<0.01)$ and cancer of the bladder $(p<0.05)$. The trend when all deaths are taken together is also statistically significant $(p<0.05)$. Because of the strong effect of age when started smoking on the risk of lung cancer we reanalysed the relation between the amount of tobacco smoked and lung cancer for different types of smoking. Compared to the result without standardisation for age when started smoking (fig 1), the inclusion of this factor led to an even closer similarity in the lung cancer death rates between cigarette, pipe, and cigar smokers in relation to quantity smoked in 1963.

The 1963 questionnaire contained a question, put to cigarette smokers only, on mode of inhalation. Shown in table 4 are the relative death rates for lung cancer, ischaemic heart disease, and all causes by mode of inhalation. The rates have been standardised for age, residence, quantity smoked in 1963, and age when
Table 2 Relative death rate for selected causes in Swedish men, 1964-79, by type of smoking*

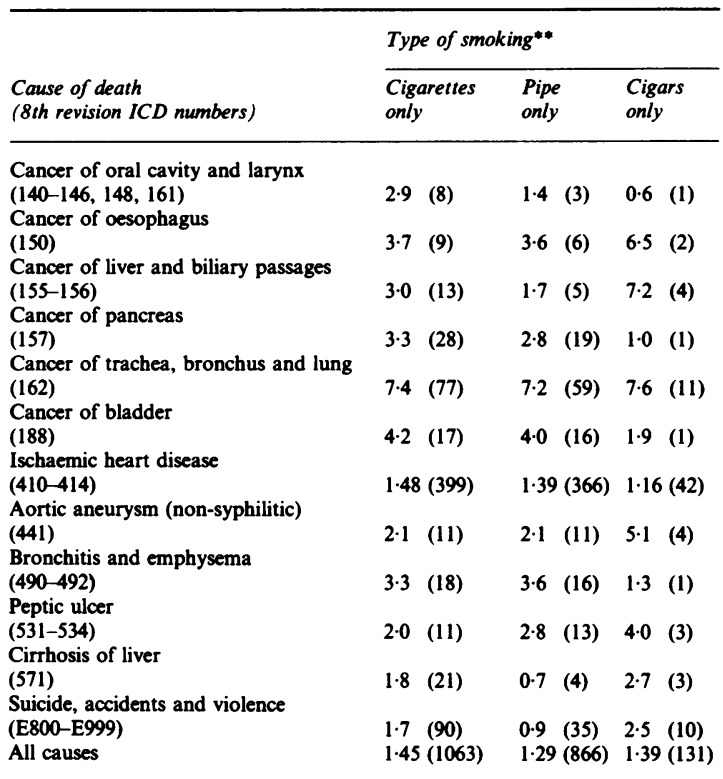

- Death rates standardised for age and residence. Never-smokers constitute the reference group. Number of deaths are given in parentheses.

** The mean grams of tobacco smoked per day in 1963, standardised for age and residence, was estimated to be 10.7 in cigarette smokers, 8.4 in pipe smokers, and 13.5 in cigar smokers.

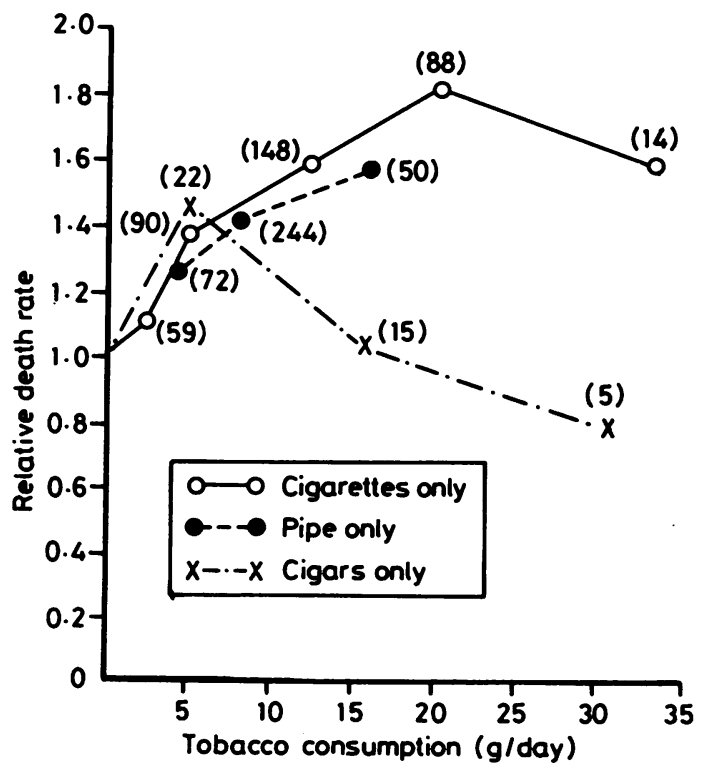

Fig 2 Relative death rate for ischaemic heart disease in Swedish men in relation to amount and type of smoking. (Death rates are standardised for age and residence with never-smokers as reference. Number of deaths are given in parentheses). 
Table 3 Relative death rate for selected causes in male Swedish smokers by age when started smoking*

\begin{tabular}{|c|c|c|c|c|}
\hline \multirow{3}{*}{$\begin{array}{l}\text { Cause of death } \\
\text { (8th revision ICD numbers) } \\
\text { Cancer of oral cavity and larynx }(140-146,148,161)\end{array}$} & \multicolumn{3}{|c|}{ Age when started smoking (years) } & \multirow{2}{*}{$\begin{array}{l}\text { Chi-square } \\
\text { valuet }\end{array}$} \\
\hline & $>25$ & $20-24$ & $<20$ & \\
\hline & $1.0(2)$ & $0.6 \quad(3)$ & $1 \cdot 1 \quad(14)$ & $0 \cdot 2$ \\
\hline Cancer of oesophagus (150) & 1.0 (1) & 1.5 (4) & $3 \cdot 2(23)$ & $2 \cdot 8$ \\
\hline Cancer of liver and biliary passages (155-156) & $1.0 \quad(7)$ & $0.4(7)$ & $0.5 \quad(22)$ & 0.8 \\
\hline Cancer of pancreas (157) & $1.0(8)$ & $0.7(12)$ & $0.9 \quad(40)$ & $0 \cdot 2$ \\
\hline Cancer of trachea, bronchus and lung (162) & $1.0(6)$ & $3 \cdot 1 \quad(49)$ & $4 \cdot 7 \quad(183)$ & $21 \cdot 3$ \\
\hline Cancer of bladder (188) & 1.0 (1) & 4.0 (9) & $6.4(33)$ & $5 \cdot 2$ \\
\hline Ischaemic heart disease $(410-414)$ & $1.00(140)$ & $1.01(320)$ & $1.07(796)$ & $1 \cdot 1$ \\
\hline Aortic aneurysm (non-syphilitic) (441) & $1.0(8)$ & $0.3(6)$ & 0.6 (27) & $0 \cdot 1$ \\
\hline Bronchitis and emphysema $(490-492)$ & 1.0 (1) & 4.9 (12) & $6.2 \quad(37)$ & 3.7 \\
\hline Peptic ulcer $(531-534)$ & $1.0(5)$ & $0.8 \quad(10)$ & $0.9(26)$ & 0.0 \\
\hline Cirrhosis of liver (571) & $1.0 \quad(3)$ & $0.9(8)$ & $1 \cdot 2 \quad(32)$ & 0.4 \\
\hline Suicide, accidents and violence (E800-E999) & $1.0 \quad(22)$ & $0.9(52)$ & $0.9 \quad(154)$ & $0 \cdot 1$ \\
\hline All causes & $1.00(345)$ & $0.97(780)$ & $1.07(2082)$ & $4 \cdot 2$ \\
\hline
\end{tabular}

- Death rates standardised for age, residence, and amount smoked. Those started smoking after the age of 24 constitute the reference group. Numbers of deaths are given in parentheses.

+ Test for trend. The groups are coded 1,2 , and 3, respectively.

started smoking. Except for all causes, no significant trend in death rates with increasing degree of inhalation could be found, although the point estimates for both lung cancer and ischaemic heart disease show an increasing trend.

The relation between mode of inhalation and lung cancer risk was also studied in different groups according to quantity of tobacco smoked. The relative death rate of lung cancer in smokers who reported that they inhaled deeply (with other smokers as reference group) was estimated at $1 \cdot 4,1 \cdot 1$, and $1 \cdot 3$ among those who smoked 1-15, 16-25, and more than $25 \mathrm{~g}$ tobacco per day, respectively.

No information on inhalation in pipe smokers or cigar smokers was available from the 1963 survey. The data from the twin questionnaire, however, show that of 1474 men smoking only cigarettes $82 \%$ reported inhalation. In 1129 smoking only pipe $85 \%$ stated that they inhaled.

\section{Discussion}

The relative risks for several smoking related diseases, including lung cancer, have been reported to be lower in cigar and pipe smokers than in cigarette smokers. ${ }^{2-6}$ These results were mostly obtained in studies performed in the United Kingdom and United States, where the proportion of inhalers is substantially higher among cigarette smokers than among smokers of cigars or pipes. ${ }^{2021}$ In the present study we found similar risks of lung cancer in cigarette, pipe, and cigar smokers, controlling for amount of tobacco consumed, age when started smoking, and urban/rural residence. The similar proportion of inhalers among Swedish cigarette and pipe smokers may partly explain our results. No information was available on inhalation patterns in Swedish cigar smokers.

Furthermore, we found similar relative risks of death from ischaemic heart disease in cigarette and pipe smokers. On the other hand, cigar smokers did not seem to experience a similar dose-related increase in risk of ischaemic heart disease. The results of other authors are not fully consistent with regard to the risks of coronary heart disease in cigarette, pipe, and cigar smokers. ${ }^{3621-24} \mathrm{~A}$ difference in the distribution of other risk factors for ischaemic heart disease between the studies and smoking groups probably contributes to the diverging results.

Measurements of carboxyhaemoglobin concentrations in British smokers show that pipe and cigar smokers have lower levels than cigarette smokers. ${ }^{25} 26$ This seems to be related primarily to the low concentrations in those pipe and cigar smokers who

Table 4 Relative death rate for selected causes in male Swedish cigarette smokers by self-described degree of inhalation*

\begin{tabular}{|c|c|c|c|c|}
\hline \multirow[b]{2}{*}{$\begin{array}{l}\text { Cause of death } \\
\text { (8th revision ICD numbers) }\end{array}$} & \multicolumn{3}{|l|}{ Inhalation } & \multirow[b]{2}{*}{$\begin{array}{l}\text { Chi-square } \\
\text { valuet }\end{array}$} \\
\hline & $\begin{array}{l}\text { Do not } \\
\text { inhale }\end{array}$ & $\begin{array}{l}\text { Inhale } \\
\text { lightly }\end{array}$ & $\begin{array}{l}\text { Inhale } \\
\text { deeply }\end{array}$ & \\
\hline $\begin{array}{l}\text { Cancer of trachea, bronchus and lung (162) } \\
\text { Ischaemic heart disease ( } 410-414) \\
\text { All causes }\end{array}$ & $\begin{array}{ll}1.0(4) \\
1.0(41) \\
1.00(118)\end{array}$ & $\begin{array}{ll}1.5 & (66) \\
1.2 & (366) \\
1.01 & (916)\end{array}$ & $\begin{array}{ll}1.8 & (76) \\
1 \cdot 3 & (309) \\
1 \cdot 11 & (868)\end{array}$ & $\begin{array}{l}2 \cdot 2 \\
2 \cdot 8 \\
5 \cdot 0\end{array}$ \\
\hline
\end{tabular}

- Death rates standardised for age and residence, amount smoked, and age when started smoking. Those who do not inhale constitute the reference gorup. Numbers of deaths are given in parentheses.

$\uparrow$ Test for trend. The groups are coded 1,2 , and 3, respectively. 
have previously not smoked cigarettes, and support the data on self-described inhalation. Only one Swedish study is available in which carboxyhaemoglobin levels have been reported for different types of smokers. ${ }^{27}$ The results show somewhat lower levels among pipe smokers than among cigarette smokers, but this difference disappears when the amount of tobacco consumed is also taken into consideration (Janzon $\mathrm{L}$, personal communication). Cigar smokers tended to have lower carboxyhaemoglobin than cigarette or pipe smokers, but their consumption was not recorded. It is not known to what extent these data are also valid for our cohort, which was markedly older and had a different geographical distribution.

It should be pointed out that the categories "pure cigarette smoker", "pure pipe smoker", and "pure cigar smoker" used in our study do not refer to lifetime smoking habits since the questionnaire of 1963 did not contain any information on type of smoking before 1954. However, judging from the data between 1954 and 1963 in the questionnaire the proportion changing their smoking habits would be expected to be low. Furthermore, the effect of smoking diminished with an increasing number of years since "exposure" cessation, ${ }^{36}$ although some data indicate that cigarette smokers retain their inhalation practices even after switching to other types of smoking. ${ }^{26}$ Changes in types of smoking after 1963 were probably also of limited importance, for example, only $11 \%$ of the cigarette smokers in 1963 had changed to pipe in 1969. ${ }^{9}$

Several factors may confound the association between smoking and the causes of mortality under study. Some factors relating to life-style and exposures in the general environment were probably partly controlled in the standardisation for urban/rural residence. Residual confounding by alcohol consumption may contribute to the increased risks in smokers for cancer of the oral cavity and larynx, oesophagus, and liver as well as deaths due to liver cirrhosis, suicide, accidents, and violence. Furthermore, it has been shown that law violations related to alcohol use were $40-50 \%$ more common among cigarette smokers than among pipe smokers in the study cohort, ${ }^{9}$ indicating a higher consumption in the former group. This would contribute to the differences in risk for alcohol-related diseases between cigarette and pipe smokers.

There was no clear effect by self-described degree of inhalation on the risk of death from lung cancer or on the risk of death from ischaemic heart disease. Previous studies have shown diverging results on the role of inhalation in smokers. ${ }^{392-30}$ The estimated degree of inhalation in the present study was based on questionnaire responses by the study subjects. Poor precision in this estimate would lessen the probability of detecting any differences in risk even if such exist.

No evidence of a threshold in the risk of lung cancer was found in the low exposure categories, although it should be pointed out that the risk estimates were unstable because of small numbers. This is of interest in relation to the effects discussed in subjects heavily exposed to environmental tobacco smoke. The weighted average relative risk for lung cancer in non-smokers associated with marriage to a smoker in the published epidemiological studies is $1 \cdot 5 .^{31}$ Exposure estimates among passive smokers ${ }^{31} 32$ and the lung cancer risks in light smokers suggest that the relative risks reported in passive smokers are not unrealistic.

In conclusion, most of our results are consistent with those of previous studies on mortality in smokers. Unlike many other authors however, we find that men smoking pipe or cigars experience a risk of death similar to that of cigarette smokers for most smoking related causes. This can probably be explained to some extent by differences in smoking habits between Swedish pipe or cigar smokers and such smokers in other countries.

Correspondence to: John Carstensen, Department of Cancer Epidemiology, Radiumhemmet, S-104 01 Stockholm, Sweden

\section{References}

${ }^{1}$ Surgeon General. Smoking and health: a report of the Surgeon General. Washington, DC: US Department of Health, Education and Welfare, 1979; DHEW publication no. (PHS)79-50066.

${ }^{2}$ Best EWR. A Canadian study of smoking and health. Ottawa: Department of National Health and Welfare, 1966.

${ }^{3}$ Doll R, Peto R. Mortality in relation to smoking: 20 years' observations on male British doctors. Br Med J 1976; 2: 1525-36.

${ }^{4}$ Hammond EC, Horn D. Smoking and death rates-Report of forty-four months of follow-up of 187,783 men. II. Death rates by cause. JAMA 1958; 166: 1294-308.

${ }^{5}$ Hammond EC, Seidman H. Smoking and cancer in the United States. Preventive Medicine 1980; 9: 169-73.

6 Rogot E, Murray JL. Smoking and causes of death among U.S. veterans: 16 years of observation. Public Health Rep 1980; 95: 213-22.

${ }^{7}$ Randig K. Zür Âtiologie des Lungenkrebses. Dtsch Med Wschr 1955; 80: 718-24.

${ }^{8}$ Abelin T, Gsell OR. Relative risk of pulmonary cancer in cigar and pipe smokers. Cancer 1967; 20: 1288-96.

${ }^{9}$ Cederlöf R, Friberg L, Hrubec Z, Lorich U. The relationship of smoking and some social covariables to mortality and cancer morbidity. A ten year follow-up in a probability sample of 55,000 subjects, age 18 to 69. Parts 1 and 2. Stockholm: Department of Environmental Hygiene, the Karolinska Institute, 1975. 
${ }^{10}$ Damber L, Larsson L-G. Smoking and lung cancer with special regard to type of smoking and type of cancer. A case-control study in north Sweden. Br J Cancer 1986; 53: 673-81.

11 Rökvanor i Sverige. En postenkätundersökning våren 1963. (Smoking habits in Sweden. A mail survey-Spring 1963.) Stockholm: Statistiska Centralbryån, Utredningsinstitutet, 1965. (In Swedish with summary in English).

${ }^{12}$ Leander EO. Rökning och dödlighet. En prospektiv undersökning samt några därmed sammanhängande metodproblem. Stockholm: Institute of Statistics, University of Stockholm, 1973. Dissertation. (In Swedish).

${ }^{13}$ World Health Organisation. Manual of the international statistical classification of diseases, injuries and causes of death. 7th revision. Geneva: WHO, 1957.

14 World Health Organisation. Manual of the international statistical classification of diseases, injuries and causes of death. 8th revision. Geneva: WHO, 1967.

15 Swedish National Central Bureau of Statistics. Classification of causes of death in Swedish statistics. Reports on statistical co-ordination. Stockholm 1973; No 1973: 11. (In Swedish).

${ }^{16}$ Cederlöf $\mathbf{R}$. The twin method in epidemiologic studies on chronic disease. Stockholm: Karolinska Institute, 1966. Dissertation.

${ }^{17}$ Cederlöf R, Friberg L, Lundman T. The interactions of smoking, environment and heredity and their implications for disease etiology. A report of epidemiological studies on the Swedish Twin Registries. Acta Med Scand 1977; Supplementum 612: 1-128.

${ }^{18}$ Breslow NE. Elementary methods of cohort analysis. Int $J$ Epidemiol 1984; 13: 112-5.

${ }^{19}$ Hakulinen T. A Mantel-Haenszel statistic for testing the association between a polychotomous exposure and a rare outcome. Am J Epidemiol 1981; 113: 192-7.

${ }^{20}$ Doll R, Hill AB. Mortality in relation to smoking: Ten years' observations of British doctors (Part 1). Br Med J 1964; 1: 1399-410.
${ }^{21}$ Hammond EC. Smoking in relation to the death rates of one million men and women. National Cancer Institute Monograph No. 19. Bethesda, Maryland: NIH, 1966: 127-204.

${ }^{22}$ Schimmler W, Neff C, Schimert G. Risikofaktoren und Herzinfarkt. Eine retrospektive Studie. Münch Med Wschr 1968; 110: 1585-94.

${ }^{23}$ Hood B, Tibblin G, Welin G, Örndahl G, KorsanBengsten K. Myocardial infarction in early age. III Coronary risk factors and their deficient control. Acta Med Scand 1969; 185: 241-51.

${ }^{24}$ Shapiro S, Weinblatt E, Frank CW, Sayer RV. Incidence of coronary heart disease in a population insured for medical care (HIP). Myocardial infarction, angina pectoris, and possible myocardial infarction. $A m J$ Publ Hlth 1969; 59: (suppl Pt 2): 1-101.

${ }^{25}$ Wald JN, Idle M, Boreham J, Bailey A. Carbon monoxide in breath in relation to smoking and carboxyhaemoglobin levels. Thorax 1981; 36: 366-9.

26 Turner JA McM, McNicol MW, Sillett RW. Distribution of carboxyhaemoglobin concentrations in smokers and nonsmokers. Thorax 1986; 41: 25-7.

27 Janzon L, Lindell S-E, Trell E, Larme P. Smoking habits and carboxyhaemoglobin. A cross-sectional study of an urban population of middle-aged men. $J$ Epidemiol Community Health 1981; 35: 271-3.

${ }^{28}$ Higenbottam T, Shipley MJ, Rose G. Cigarettes, lung cancer, and coronary heart disease: the effects of inhalation and tar yield. $J$ Epidemiol Community Health 1982; 36: 113-7.

${ }^{29}$ Lubin JH, Blot WJ, Berrino F, et al. Pattern of lung cancer risk according to type of cigarette smoked. Int $J$ Cancer 1984; 33: 569-76.

${ }^{30}$ Benhamou S, Benhamou E, Tirmarche M, Flamant R. Lung cancer and use of cigarettes: a French case-control study. J Natl Cancer Inst 1985; 74: 1169-75.

${ }^{31}$ Pershagen G. Review of epidemiology in relation to passive smoking. Arch Toxicol 1986; suppl 9: 63-73.

32 Vutuc C. Lung cancer risk and passive smoking: Quantitative aspects. Zbl Bakt Hyg 1983; 177: 90-5. 